El título esta publicación es contundente, pues denomina a los asentamientos que se desarrollaron hacia el año 3,000 a. C. en el valle de Supe, fruto de una civilización con nombre propio: Caral.

Son nueve los centros urbanos del valle de Supe que se consideran en esta publicación realizada por Ruth Shady y su equipo profesional.

Los descubrimientos realizados durante los últimos 15 años en el valle de Supe (y Vichama, en la costa de Huaura) por la arqueóloga Ruth Shady y su equipo de trabajo han sido tan vastos que le han permitido plantear la existencia de un sistema social (última frase del título).

El volumen está dividido en tres secciones. La primera (capítulos 1 y 2) revisa de forma abreviada los inicios y el desarrollo de las investigaciones en el valle de Supe, y culmina con mapas y fotos que ubican los asentamientos hallados. Al respecto, es importante precisar la filiación cultural predominante, ya que se ubica a las construcciones monumentales precerámicas dentro del período Formativo Inicial. La nueva tendencia de considerar el periodo Arcaico Superior más bien como Formativo Inicial, seguida por varios arqueólogos, en cierta manera se consolidó con la reunión que tuvo lugar en enero de 2011 en el Museo Nacional de Arqueología, Antropología e Historia del Perú (MNAAHP) donde un grupo de importantes arqueólogos peruanos y extranjeros acordaron utilizar esa denominación.

Gracias a la cantidad de avances arqueológicos de los últimos años, encabezados por los del valle de Supe, ha resultado evidente que la complejidad y estadío de desarrollo demuestran que los sitios antes considerados dentro del periodo llamado Precerámico Tardío corresponden en realidad a una etapa Formativa. Sin embargo, la terminología Formativo Inicial, propuesta inicialmente por Yoshio Onuki (1999), aunque conceptualmente válida, genera confusión, ya que el periodo que le sigue es el denominado Formativo Temprano (o Inferior), proveniente de la periodificación de Lumbreras, que coincide con el denominado periodo Inicial de Rowe-Lanning. La repetición de los términos formativo e inicial en la designación del periodo previo resulta en una denominación poco clara y precisa. Por lo tanto, llamarle Formativo

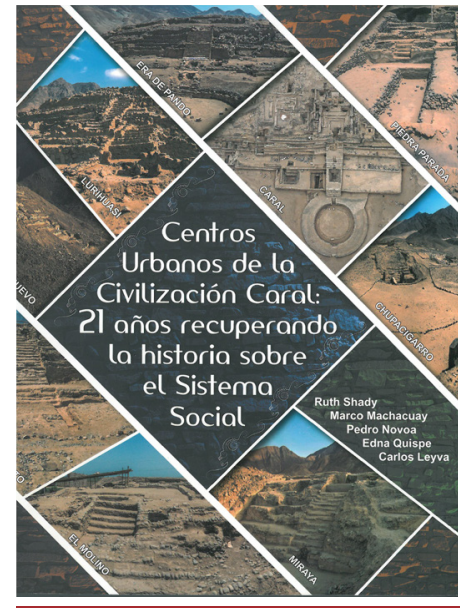

\section{CENTROS URBANOS DE LA CIVILIZACIÓN CARAL: 21 AÑOS RECUPERANDO LA HISTORIA SOBRE EL SISTEMA SOCIAL}

\author{
CARLOS LEYVA, MARCO MACHACUAY, PEDRO \\ NOVOA, EDNA QUISPE Y RUTH SHADY
}

ZONA ARQUEOLÓGICA CARAL, UE 003 - MINISTERIO DE CULTURA, LIMA, PERÚ, 2015.

\section{RESEÑA DE CARLOS ENRIQUE GUZMÁN GARCÍA}

Precerámico, como lo precisa el equipo del Proyecto Arqueológico Orcon-Pacaybamba es lo más conveniente, porque dicha terminología no conlleva a ningún tipo de confusión, y refuerza la particularidad andina que forjó sociedades complejas y con arquitectura monumental antes de conocer la cerámica. En todo caso, parece haber consenso en cuanto a considerar la etapa que inicia 3,000 años a. C. dentro del periodo Formativo.

La segunda parte es la sección central y más extensa del libro (capítulo 3), el cual está dedicado a los centros urbanos señalados en el título. El primero de los nueve centros que se analiza es Caral, que a lo largo de la publicación se reconoce como ciudad sagrada, ciudad capital de la zona capital (sección media-baja del valle de Supe) y el centro urbano más destacado de la civilización caral.

Tanto en Caral como en los otros sitios revisados (Chupacigarro, Miraya, Lurihuasi, Allpacoto, Pueblo Nuevo, Piedra Parada, El Molino y Era de Pando) se acredita ocupación desde el periodo Formativo Inicial (o Formativo Precerámico) hasta el Intermedio Temprano. Caral, al Oeste, registra incluso ocupación que corresponde al Intermedio Tardío.

La tercera parte del libro (capítulos 4 a 8) resume los esfuerzos llevados a cabo por la doctora Ruth Shady y su equipo en cuanto a los trabajos de excavación, conservación, labor multidisciplinaria, uso de tecnología, participación y compromiso de la población local, planes, metas y difusión de los importantes descubrimientos entre la comunidad.
Los avances realizados durante los últimos años en Supe han permitido descubrir más estructuras residenciales, productivas y públicas menores. No obstante, si se compara los dos sitios que albergan la mayor cantidad de estas, Caral y Lurihuasi, con casos de ciudades del Intermedio Tardío como las huacas de Moche y Pampa Grande, la densidad de los primeros se revela mínima, muy lejos de alcanzar a las ciudades mochicas.

Caral más parece un centro con pirámides y plazas donde se daban actividades rituales, acompañadas de estructuras residenciales de élite, y edificios públicos menores o multiusos. Los talleres o lugares destinados a actividades productivas son escasos, apenas un grupo de pequeños recintos periféricos denominados talleres de especialización artesanal $\mathrm{J}$, mientras que las residencias populares son también un reducido grupo emplazado en la periferia oeste. Tomando en cuenta esto, es posible plantear que si en Caral, además de las pirámides, se considera que las residencias de élite, y los "edificios públicos menores o multiusos" tuvieron población residente permanente, se trata de un centro "religioso" de élite (de amplia influencia), al cual, haciendo un paralelo (salvando distancias) con la Ciudad del Vaticano, podría dársele la denominación sugerida por la arqueóloga peruana Ruth Shady: ciudad sagrada de Caral. 